\title{
Efficacy of trimetazidine and plasmin combined with alprostadil in treatment of lower extremity arteriosclerosis obliterans
}

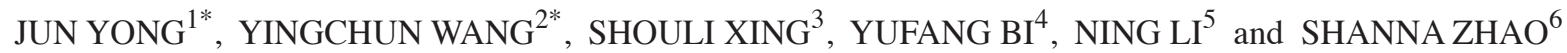 \\ ${ }^{1}$ Department of Vascular Surgery, The Affiliated Yantai Yuhuangding Hospital of Qingdao University, Yantai, \\ Shandong 264000; ${ }^{2}$ Department of Pharmacy, Yantaishan Hospital, Yantai, Shandong 264001; \\ Departments of ${ }^{3}$ Image, ${ }^{4}$ Operation Room, and ${ }^{5}$ Pathology, The People's Hospital of Zhangqiu Area, Jinan, \\ Shandong 250200; ${ }^{6}$ Department of Clinical Laboratory, Yantaishan Hospital, Yantai, Shandong 264001, P.R. China
}

Received November 14, 2018; Accepted March 18, 2019

DOI: $10.3892 / \mathrm{etm} .2019 .7476$

\begin{abstract}
Clinical efficacy of trimetazidine and plasmin combined with alprostadil in the treatment of lower extremity arteriosclerosis obliterans was investigated. A retrospective analysis was performed on 132 patients with lower extremity arteriosclerosis obliterans treated in Yantai Yuhuangding Hospital from March 2015 to August 2017. Among them, 68 patients were treated with trimetazidine combined with alprostadil (group A), and 64 patients were treated with plasmin combined with alprostadil (group B). Patients were administered 2 courses of treatment and observed with regard to therapeutic effects, changes in blood flow perfusion indicators (vascular peak velocity and blood flow) of the superficial femoral artery, posterior tibial artery and dorsalis pedis artery, in endothelial function, in left ankle brachial index, in pain-free walking distance and in maximum walking distance. After treatment, the vascular peak velocity of group B patients was lower than that in group $\mathrm{A}(\mathrm{P}<0.05)$, but the blood flow was higher than that in group $\mathrm{A}(\mathrm{P}<0.05)$. After treatment, endothelial esterase, high-sensitivity C-reactive protein and circulating endothelial cell count levels after treatment were lower than those before treatment $(\mathrm{P}<0.05)$, but nitric oxide level was higher than that before treatment $(\mathrm{P}<0.05)$. After treatment, the left ankle brachial index was lower in group $\mathrm{A}$ of patients than that in group $B(P<0.05)$. After treatment, the maximum walking distance was significantly higher in group A patients than that in group $\mathrm{B}(\mathrm{P}<0.05)$. After treatment, the pain-free walking distance and maximum walking distance of the two
\end{abstract}

Correspondence to: Dr Shanna Zhao, Department of Clinical Laboratory, Yantaishan Hospital, 91 Jiefang Road, Yantai, Shandong 264001, P.R. China

E-mail:n4q2ex@163.com

*Contributed equally

Key words: trimetazidine, plasmin, alprostadil, lower extremity arteriosclerosis obliterans, clinical efficacy groups of patients were higher than those before treatment $(\mathrm{P}<0.05)$. Both trimetazidine and plasmin combined with alprostadil can effectively treat lower extremity arteriosclerosis obliterans. The former is better than the latter in improving exercise capacity, but the latter is better than the former in improving blood flow perfusion in patients.

\section{Introduction}

Lower extremity arteriosclerosis obliterans is a chronic occlusion of lower extremity arteries, mainly common iliac artery and superficial femoral artery, caused by atherosclerosis, with a main clinical manifestation of insufficient blood supply to lower extremities $(1,2)$. One of its main risk factors is age, and the incidence increases with age. Its incidence in people over 60 years can reach $20 \%$. As the population ages and the dietary structure changes, lower extremity arteriosclerosis obliterans has become a worldwide public health problem $(3,4)$. Its prognosis is poor, especially in patients with intermittent claudication, rest pain, ulcer and gangrene, with higher 5-year mortality $(5,6)$. Therefore, it is very important to find suitable and effective treatment methods.

Surgery and interventional treatment can effectively improve arterial occlusion, but their long-term treatment effects remain unsatisfactory, especially for peripheral arterial lesion and polyplanar stenosis, and older patients are less tolerant to surgery and interventional treatment $(7,8)$. Drug treatment is a reasonable and feasible means. Drugs improving cell ischemia and energy metabolism, inhibiting platelet aggregation and improving microcirculation, such as trimetazidine, alprostadil and plasmin, have good efficacy (9-11). Alprostadil is a natural prostaglandin that inhibits platelet aggregation, promotes erythrocyte deformation and improves hemorheology (12). Trimetazidine, a piperazine derivative that can protect cell energy metabolism in ischemic conditions and ischemic cells, maintains the stability of the intracellular environment and improves the exercise tolerance of patients (13). As a proteolytic enzyme extracted from Agkistrodon blomhoffii ussurensis venom with monoclonal antibody purification technology, plasmin can directly dissolve the thrombogenic fibrin without causing excessive fibrinolysis, having excellent antithrombotic function (14). However, there are few comparative studies on 
the efficacy of trimetazidine, alprostadil and plasmin in lower extremity arteriosclerosis obliterans.

In this study, the medical records of 132 patients with lower extremity arteriosclerosis obliterans were retrospectively analyzed, and the efficacy of trimetazidine and plasmin combined with alprostadil in lower extremity arteriosclerosis obliterans was compared, in order to clinically provide reference for the drug use in the treatment of lower extremity arteriosclerosis obliterans.

\section{Patients and methods}

Study object. A retrospective analysis was performed on the medical records of 132 patients with lower extremity arteriosclerosis obliterans treated in Yantai Yuhuangding Hospital (Yantai, China) from March 2015 to August 2017. Among them, 68 patients were treated with trimetazidine combined with alprostadil (group A), 64 patients treated with plasmin combined with alprostadil (group B). The patients were in compliance with the 2015 edition of guidelines for the diagnosis and treatment of lower extremity arteriosclerosis obliterans, with obvious clinical features of lower extremity arteriosclerosis obliterans and left ankle brachial index $\leq 0.9$, and aged 40-75 years. None of the patients had autoimmune disease, severe inflammatory reaction or other parts of arteriovenous occlusion, and they had complete records. Patients with severe angina pectoris, diabetes mellitus, recurrent infection, cerebrovascular disease and peptic ulcer were excluded, as were patients with anticoagulant drugs; patients with heart failure, kidney or liver diseases; patients who had been treated with depressurization and other methods with treatment drugs affecting vascular function and coagulation mechanism.

The study was approved by the Ethics Committee of Yantai Yuhuangding Hospital. Patients or their families signed an informed consent form.

Treatment methods. All 132 patients were routinely treated, followed a controlled diet, no smoking and drinking, controlled blood lipid and blood pressure, stabilized atherosclerotic plaque, actively controlled platelet aggregation, anti-infective treatment and rehabilitation training. Patients in group A were treated with trimetazidine in combination with alprostadil, patients in group B were treated with plasmin in combination with alprostadil on this basis. The dose of alprostadil was $10 \mu \mathrm{g}+100 \mathrm{ml}$ of saline, intravenously dripped after being mixed evenly, once a day. The dose of trimetazidine was $30 \mathrm{mg}$ orally, 3 times a day. The dose of plasmin was 100 units $+250 \mathrm{ml}$ of saline, infused once a day. The treatments were a course followed over 14 days, for a total of 2 consecutive courses of treatment.

Observation indicators. Subsequent to the 2 courses of treatment the two groups of patients were observed with regard to therapeutic effects, changes in blood flow perfusion indicators (vascular peak velocity and blood flow, DCU12 full digital color Doppler ultrasound diagnostic apparatus, Xuzhou Kaixin Electronic Equipment Co., Ltd., Xuzhou, China) of the superficial femoral artery, posterior tibial artery and dorsalis pedis artery, in endothelial function (fasting blood collected by nurses in the morning and detected in the laboratory medicine of Yantai Yuhuangding Hospital), in left ankle brachial index [PeriFlux 5000 laser Doppler flowmeter; Swedish Parry Medicine (China) Co., Beijing, China], in pain-free walking distance, and in maximum walking distance.

Efficacy evaluation criteria. Evaluation criteria were as follows: Recovery: Symptoms disappeared, and dorsal blood flow, skin color, skin temperature and dorsal arterial pulse returned to normal. The maximum walking distance increased by $>100 \%$, and the left ankle brachial index was between 0.9 and 1.3. Markedly effective: Conscious symptoms, skin color, skin temperature and dorsal artery pulse were improved significantly. Pain-free and maximum walking distance increased by $>90 \%$, but $\leq 100 \%$. The left ankle brachial index was $\geq 0.9$, and the blood flow of dorsalis pedis artery increased by $>80 \%$. Effective: Conscious symptoms, skin color, skin temperature and dorsal artery pulse were improved better than those before treatment. Pain-free and maximum walking distance increased by $50-89 \%$. Left ankle brachial index increased by $0.2-0.3$, and blood flow increased by $>50 \%$. Non-effective: Conscious symptoms, skin color, skin temperature and dorsal artery pulse was not improved compared to those before treatment. Pain-free and maximum walking distance increased by $\leq 50 \%$, and no change in left ankle brachial index. The total effective rate was calculated as: recovery + markedly effective + effective.

Statistical analysis. SPSS19.0 (AsiaAnalytics Formerly SPSS China, Shanghai, China) was used. Enumeration data were expressed as [n (\%)], and $\chi^{2}$ test was used for the comparison of ratio. Measurement data were expressed as mean $\pm \mathrm{SD}$, and t-test was used for comparison between the two groups. ANOVA and LSD post hoc test for repeated measurement were used for comparison at different times in the group. $\mathrm{P}<0.05$ indicated the difference was statistically significant.

\section{Results}

General data. There were 68 patients in group A, including 42 male patients and 26 female patients, aged (62.45 \pm 9.26$)$ years, and 64 patients in group B, including 41 male patients and 23 female patients, aged $(63.33 \pm 9.17)$ years. There were no statistically significant differences in sex and age between the two groups of patients ( $\mathrm{P}>0.05)$, and in other basic data such as BMI, smoking history, proportion of hypertension patients, proportion of diabetes mellitus patients, platelet count, activated partial thromboplastin time, D-dimer and bleeding time $(\mathrm{P}>0.05)$ (Table I).

Efficacy analysis. The results of the efficacy analysis of the two groups of patients after 2 courses of treatment showed that there were no statistically significant differences in recovery rate, markedly effective rate, effective rate, non-effective rate and total effective rate between the two groups of patients (P>0.05) (Table II).

Changes in blood flow perfusion indicators. Before treatment, there were no statistically significant differences in the vascular peak velocity and blood flow of the superficial femoral artery, posterior tibial artery and dorsalis pedis artery between the two groups $(\mathrm{P}>0.05)$. After treatment, the vascular peak 
Table I. General data.

\begin{tabular}{|c|c|c|c|c|}
\hline Item & Group A $(n=68)$ & Group B $(n=64)$ & $\chi^{2 / t}$ & P-value \\
\hline $\operatorname{Sex}[\mathrm{n}(\%)]$ & & & 0.075 & 0.785 \\
\hline Male & $42(61.76)$ & $41(64.06)$ & & \\
\hline Female & $26(38.24)$ & $23(35.94)$ & & \\
\hline Age (years) & $62.45 \pm 9.26$ & $63.33 \pm 9.17$ & 0.548 & 0.585 \\
\hline BMI $\left(\mathrm{kg} / \mathrm{m}^{2}\right)$ & $25.41 \pm 4.15$ & $26.18 \pm 4.23$ & 1.055 & 0.293 \\
\hline Smoking history $[\mathrm{n}(\%)]$ & & & 0.065 & 0.799 \\
\hline Yes & $45(66.18)$ & $41(64.06)$ & & \\
\hline No & $23(33.82)$ & $23(35.94)$ & & \\
\hline Hypertension [n (\%)] & & & 0.068 & 0.795 \\
\hline Yes & $41(60.29)$ & $40(62.50)$ & & \\
\hline No & $27(39.71)$ & $24(37.50)$ & & \\
\hline Diabetes mellitus [n (\%)] & & & 0.531 & 0.466 \\
\hline Yes & $22(32.35)$ & $17(26.56)$ & & \\
\hline No & $46(67.65)$ & $47(73.44)$ & & \\
\hline Platelet count $\left(\times 10^{9} / 1\right)$ & $221.45 \pm 61.53$ & $219.68 \pm 62.56$ & 0.164 & 0.870 \\
\hline Activated partial thromboplastin time (sec) & $29.18 \pm 2.14$ & $28.94 \pm 2.31$ & 0.620 & 0.537 \\
\hline D-dimer $(\mu \mathrm{g} / \mathrm{l})$ & $362.44 \pm 128.17$ & $359.18 \pm 124.62$ & 0.148 & 0.883 \\
\hline Bleeding time (min) & $6.38 \pm 1.06$ & $6.71 \pm 1.14$ & 1.723 & 0.087 \\
\hline
\end{tabular}

Table II. Efficacy analysis of the two groups of patients after two courses of treatment [n (\%)].

\begin{tabular}{lcccc}
\hline Criteria & Group A $(\mathrm{n}=68)$ & Group B (n=64) & $\chi^{2}$ & P-value \\
\hline Recovery & $15(22.06)$ & $11(17.19)$ & 0.498 & 0.482 \\
Markedly effective & $32(47.06)$ & $33(51.56)$ & 0.268 & 0.605 \\
Effective & $18(26.47)$ & $15(23.44)$ & 0.162 & 0.688 \\
Non-effective & $3(4.41)$ & $5(7.81)$ & 0.670 & 0.413 \\
Total effective rate & $65(95.59)$ & $59(92.19)$ & 0.670 & 0.413 \\
\hline
\end{tabular}

Table III. Changes in vascular peak velocity of patients in two groups before and after treatment $(\mathrm{m} / \mathrm{sec})$.

\begin{tabular}{|c|c|c|c|c|}
\hline Artery & Group A $(n=68)$ & Group B $(n=64)$ & $\mathrm{t}$ & P-value \\
\hline \multicolumn{5}{|c|}{ Superficial femoral artery } \\
\hline Before treatment & $1.54 \pm 0.33$ & $1.56 \pm 0.34$ & 0.342 & 0.732 \\
\hline After treatment & $1.24 \pm 0.21$ & $1.32 \pm 0.19$ & 2.290 & 0.024 \\
\hline \multicolumn{5}{|c|}{ Posterior tibial artery } \\
\hline Before treatment & $1.35 \pm 0.22$ & $1.34 \pm 0.23$ & 0.255 & 0.799 \\
\hline After treatment & $1.13 \pm 0.14$ & $1.19 \pm 0.15$ & 2.377 & 0.019 \\
\hline \multicolumn{5}{|c|}{ Dorsalis pedis artery } \\
\hline Before treatment & $1.01 \pm 0.15$ & $1.00 \pm 0.14$ & 0.395 & 0.693 \\
\hline After treatment & $0.78 \pm 0.08$ & $0.81 \pm 0.09$ & 2.027 & 0.045 \\
\hline
\end{tabular}

velocity in group $\mathrm{B}$ was lower than that in group $\mathrm{A}(\mathrm{P}<0.05)$, but the blood flow was higher than that in group $\mathrm{A}(\mathrm{P}<0.05)$. The vascular peak velocity and blood flow were improved in the two groups. The vascular peak velocity of those after treatment was lower than that before treatment of patients in the two groups $(\mathrm{P}<0.05)$, but the blood flow was higher than that before treatment $(\mathrm{P}<0.05)$ (Tables III and IV).

Changes in endothelial function. There were no statistically significant differences in endothelial esterase, high-sensitivity 
Table IV. Changes in blood flow of patients in the two groups before and after treatment $(\mathrm{ml} / \mathrm{min})$.

\begin{tabular}{lllll}
\hline Artery & Group A $(\mathrm{n}=68)$ & Group B $(\mathrm{n}=64)$ & $\mathrm{t}$ & P-value \\
\hline Superficial femoral artery & & & & \\
Before treatment & $364.73 \pm 93.56$ & $368.45 \pm 92.88$ & 0.231 & 0.818 \\
After treatment & $386.18 \pm 101.24$ & $425.66 \pm 102.17$ & 2.229 & 0.028 \\
Posterior tibial artery & & & & 0.428 \\
$\quad$ Before treatment & $365.89 \pm 96.54$ & $358.77 \pm 94.43$ & 2.303 & 0.669 \\
After treatment & $398.18 \pm 105.46$ & $431.15 \pm 103.74$ & & 0.023 \\
Dorsalis pedis artery & & & 0.621 & 0.536 \\
Before treatment & $22.46 \pm 8.17$ & $21.59 \pm 7.92$ & 2.245 & 0.027 \\
After treatment & $28.03 \pm 10.58$ & $32.25 \pm 11.02$ & & \\
\hline
\end{tabular}

Table V. Changes in endothelial function of patients in the two groups before and after treatment.

\begin{tabular}{lcccr}
\hline & Group A (n=68) & Group B (n=64) & $\mathrm{t}$ & P-value \\
\hline Endothelial esterase (ng/l) & & & & \\
$\quad$ Before treatment & $71.62 \pm 7.25$ & $72.33 \pm 7.46$ & 0.555 & 0.580 \\
$\quad$ After treatment & $62.59 \pm 6.24$ & $63.78 \pm 6.51$ & 1.072 & 0.286 \\
High-sensitivity C-reactive protein (mg/l) & & & & \\
$\quad$ Before treatment & $3.25 \pm 1.26$ & $3.33 \pm 1.21$ & 0.372 & 0.711 \\
After treatment & $2.28 \pm 1.13$ & $2.19 \pm 1.06$ & 0.471 & 0.638 \\
Nitric oxide $(\mu$ mol/l) & & & & \\
Before treatment & $50.72 \pm 5.25$ & $52.13 \pm 5.18$ & 1.552 & 0.123 \\
After treatment & $59.64 \pm 5.85$ & $60.77 \pm 6.12$ & 1.085 & 0.280 \\
Circulating endothelial cell count & & & & \\
Before treatment & $7.82 \pm 3.06$ & $7.76 \pm 3.12$ & 0.111 & 0.911 \\
After treatment & $4.25 \pm 1.58$ & $4.17 \pm 1.46$ & 0.302 & 0.763 \\
\hline
\end{tabular}

C-reactive protein, nitric oxide and circulating endothelial cell count levels between the two groups before and after treatment $(\mathrm{P}>0.05)$. After treatment, the levels were improved in the two groups. Endothelial esterase, high-sensitivity C-reactive protein and circulating endothelial cell count levels after treatment were lower than those before treatment $(\mathrm{P}<0.05)$, but nitric oxide level was higher than that before treatment $(\mathrm{P}<0.05)($ Table V).

Changes in left ankle brachial index. There was no statistically significant difference in left ankle brachial index between the two groups of patients before treatment $(\mathrm{P}>0.05)$. After treatment, the left ankle brachial index was lower in group $A$ than that in group $\mathrm{B}(\mathrm{P}<0.05)$, and was improved in the two groups. The index was higher after treatment than that before treatment in the two groups $(\mathrm{P}<0.05)$ (Fig. 1).

Changes in pain-free and maximum walking distance change. There were no statistically significant differences in pain-free walking distance between the two groups before and after treatment $(\mathrm{P}>0.05)$, and in maximum walking distance before treatment $(\mathrm{P}>0.05)$. After treatment, the maximum walking distance was significantly higher in group $\mathrm{A}$ than that in group $\mathrm{B}$ $(\mathrm{P}<0.05)$. After treatment, the pain-free walking distance and

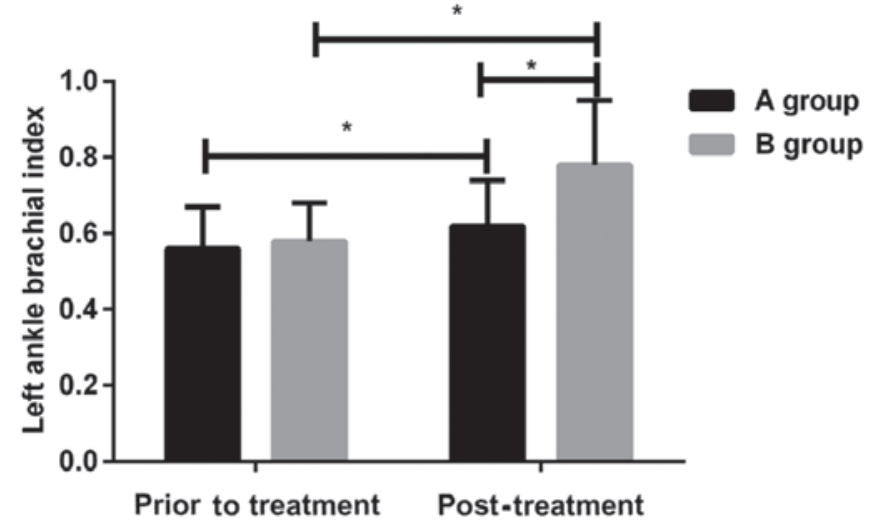

Figure 1. Changes in left ankle brachial index of patients in two groups before and after treatment. There was no statistically significant difference in left ankle brachial index of patients between the two groups before treatment $(\mathrm{P}>0.05)$. After treatment, the left ankle brachial index was lower in group A than that in group $\mathrm{B}(\mathrm{P}<0.05)$. It was improved in the two groups after treatment. The index was higher after treatment than that before treatment in the two groups of patients $(\mathrm{P}<0.05)$. ${ }^{*} \mathrm{P}<0.05$.

maximum walking distance of the two groups of patients were improved and were higher than those before treatment $(\mathrm{P}<0.05)$ (Table VI). 
Table VI. Changes in pain-free and maximum walking distance of patients in two groups before and after treatment.

\begin{tabular}{lcccr}
\hline & Group A (n=68) & Group B (n=64) & $\mathrm{t}$ & P-value \\
\hline Pain-free walking distance (m) & & & & 0.609 \\
$\quad$ Before treatment & $145.67 \pm 21.26$ & $147.62 \pm 22.37$ & 0.514 & 0.160 \\
After treatment & $448.59 \pm 93.34$ & $471.63 \pm 94.11$ & 1.412 & 0.885 \\
Maximum walking distance (m) & & & & 0.145 \\
Before treatment & $953.65 \pm 348.27$ & $962.49 \pm 351.64$ & 2.396 & 0.018 \\
After treatment & $1,347.63 \pm 321.48$ & $1,223.65 \pm 268.72$ & & \\
\hline
\end{tabular}

\section{Discussion}

Lower extremity arteriosclerosis obliterans is a very common systemic peripheral vascular disease in clinical practice. The formation of atherosclerotic plaque causes different degrees of stenosis in the arterial tube of patients and even complete occlusion, blocking blood flow and leading to limb ischemic injury, so the condition of lower extremity arteriosclerosis obliteration is complicated, with high disability rate and mortality $(15,16)$. Many studies have reported that trimetazidine or plasmin in combination with alprostadil has better efficacy in the treatment of arteriosclerosis obliterans $(17,18)$. However, there are few comparative studies on the efficacy of trimetazidine and plasmin in combination with alprostadil. In this study, the efficacy of trimetazidine and plasmin in combination with alprostadil was analyzed, and differences in the efficacy of the two methods were explored, in order to provide reference for clinical treatment.

In the study, the medical records of 132 patients with lower extremity arteriosclerosis obliterans were selected in strict accordance with inclusion and exclusion criteria. There was no statistically significant difference in the general data of patients between the two groups. Their data are comparable in this study, and the results have a certain degree of credibility. The results of the efficacy analysis of the two groups of patients showed that there were no significant differences in the recovery rate, markedly effective rate, effective rate, non-effective rate and total effective rate between the two groups, suggesting that the two treatments have similar efficacy. Then, changes in blood flow perfusion-related indicators were further analyzed in the two groups. It was found that the degree of improvement of the vascular peak velocity and blood flow of the superficial femoral artery, posterior tibial artery and dorsalis pedis artery, and the left ankle brachial index of patients in B group was better than that in group A. The results of the pain-free and maximum walking distance analysis of the two groups showed that the maximum walking distance after treatment in group A was higher than that in group B, but there was no difference in pain-free walking distance and in the comparison results of endothelial function between the two groups after treatment in this study.

At present, there are few studies on the efficacy of trimetazidine or plasmin in combination with alprostadil in the treatment of lower extremity arteriosclerosis obliterans worldwide. Therefore, there is still uncertainty in the efficacy comparison between the two treatments in this study. It is hoped that this study will promote more scholars to participate in the analysis of the efficacy of trimetazidine and plasmin combined with alprostadil in lower extremity arteriosclerosis obliterans, providing better reference for clinical treatment. The mechanisms of action of trimetazidine, alprostadil and plasmin in the treatment of lower extremity arteriosclerosis obliterans are not the same (12-14). It can be seen from the results that both treatments can improve blood flow perfusion in patients, which may be caused by alprostadil promoting fibrinolysis. In some studies of vascular diseases, it can improve tissue plasminogen activator and its inhibitor levels, promoting fibrinolysis, and alprostadil also has vasodilation effects $(19,20)$; thus, blood flow perfusion indicators in group A are improved compared to those before treatment. However, there are few reports on the pro-fibrinolytic effect of trimetazidine. The pro-fibrinolytic effect of plasmin is obvious, and can effectively clear blocked blood vessels, so blood flow perfusion indicators in group B of patients are better than those in group A. This may also be the reason for the left ankle brachial index in group B being better than that in group A. The effect of trimetazidine on improving cell energy metabolism has been recognized, so this may be the main reason why patients in group A have longer maximum walking distance after treatment than patients in group B. Although plasmin can dissolve thrombus and improve blood flow perfusion, this improvement may not be as obvious as that of trimetazidine due to the duration of treatment (21). This is the shortcoming of this study, i.e., that only the short-term efficacy was evaluated. Further follow-up reports are to be performed to analyze the long-term efficacy of the two treatments. Differences in pain-free walking distance and endothelial function-related indicators between the two groups after treatment were not found. Both treatments are effective in improving symptoms, but neither trimetazidine nor plasmin has any analgesic effect. This may be the reason why there is no difference in pain-free walking distance between the two groups of patients after treatment. Trimetazidine has been reported to be able to improve endothelial function (22), and plasmin also to be able to promote endothelial progenitor cell production, repair vascular damage and improve endothelial function (23). The results of the current study showed that the degree of improvement of the two drugs in endothelial function was similar, but all the results had not been verified. Therefore, it is hoped that this study will promote more scholars to participate in the analysis of the efficacy of trimetazidine and plasmin combined with alprostadil in lower extremity arteriosclerosis 
obliterans, to validate our results and provide better reference for clinical treatment.

In conclusion, both trimetazidine and plasmin combined with alprostadil can effectively treat lower extremity arteriosclerosis obliterans. The former is better than the latter in improving exercise capacity, but the latter is better than the former in improving blood flow perfusion in patients.

\section{Acknowledgements}

Not applicable.

\section{Funding}

No funding was received.

\section{Availability of data and materials}

The datasets used and/or analyzed during the current study are available from the corresponding author on reasonable request.

\section{Authors' contributions}

JY and YW drafted the manuscript and worked on the treatment methods. SX and YB were responsible for observation indicators analysis. NL and SZ assisted with efficacy evaluation and revised the manuscript. All authors read and approved the final manuscript.

\section{Ethics approval and consent to participate}

This study was approved by the Ethics Committee of Yantai Yuhuangding Hospital (Yantai, China). Patients who participated in this research had complete clinical data. Signed informed consents were obtained from the patients or the guardians.

\section{Patient consent for publication}

Not applicable.

\section{Competing interests}

The authors declare that they have no competing interests.

\section{References}

1. Conte MS, Pomposelli FB, Clair DG, Geraghty PJ, McKinsey JF Mills JL, Moneta GL, Murad MH, Powell RJ, Reed AB, et al; Society for Vascular Surgery Lower Extremity Guidelines Writing Group; Society for Vascular Surgery: Society for Vascular Surgery practice guidelines for atherosclerotic occlusive disease of the lower extremities: Management of asymptomatic disease and claudication. J Vasc Surg 61 (Suppl): S2-S41, 41S.e1, 2015.

2. Gerhard-Herman MD, Gornik HL, Barrett C, Barshes NR, Corriere MA, Drachman DE, Fleisher LA, Fowkes FG, Hamburg NM, Kinlay S, et al: 2016 AHA/ACC Guideline on the Management of Patients With Lower Extremity Peripheral Artery Disease: Executive summary: A report of the American College of Cardiology/American Heart Association Task Force on Clinical Practice Guidelines. J Am Coll Cardiol 69: 1465-1508, 2017.
3. Hinchliffe RJ, Brownrigg JR, Apelqvist J, Boyko EJ, Fitridge R, Mills JL, Reekers J, Shearman CP, Zierler RE and Schaper NC; International Working Group on the Diabetic Foot: IWGDF guidance on the diagnosis, prognosis and management of peripheral artery disease in patients with foot ulcers in diabetes. Diabetes Metab Res Rev 32 (Suppl 1): 37-44, 2016.

4. Jaff MR, White CJ, Hiatt WR, Fowkes GR, Dormandy J, Razavi M, Reekers J and Norgren L: An update on methods for revascularization and expansion of the TASC lesion classification to include below-the-knee arteries: A supplement to the Inter-Society Consensus for the Management of Peripheral Arterial Disease (TASC II): The TASC Steering Comittee. Ann Vasc Dis 8: 343-357, 2015.

5. McDermott MM: Lower extremity manifestations of peripheral artery disease: The pathophysiologic and functional implications of leg ischemia. Circ Res 116: 1540-1550, 2015.

6. Zhang X, Hu Y, Zeng H, Li L, Zhao J, Zhao J, Liu F, Bao Y and Jia W: Serum fibroblast growth factor 21 levels is associated with lower extremity atherosclerotic disease in Chinese female diabetic patients. Cardiovasc Diabetol 14: 32, 2015.

7. Aboyans V, Ricco JB, Bartelink MEL, Björck M, Brodmann M, Cohnert T, Collet JP, Czerny M, De Carlo M, Debus S, et al; ESC Scientific Document Group: 2017 ESC Guidelines on the Diagnosis and Treatment of Peripheral Arterial Diseases, in collaboration with the European Society for Vascular Surgery (ESVS): Document covering atherosclerotic disease of extracranial carotid and vertebral, mesenteric, renal, upper and lower extremity arteries. Endorsed by the European Stroke Organization (ESO)The Task Force for the Diagnosis and Treatment of Peripheral Arterial Diseases of the European Society of Cardiology (ESC) and of the European Society for Vascular Surgery (ESVS). Eur Heart J 39: 763-816, 2018.

8. Patel MR, Conte MS, Cutlip DE, Dib N, Geraghty P, Gray W, Hiatt WR, Ho M, Ikeda K, Ikeno F, et al: Evaluation and treatment of patients with lower extremity peripheral artery disease: Consensus definitions from Peripheral Academic Research Consortium (PARC). J Am Coll Cardiol 65: 931-941, 2015.

9. Chu YS, Li DX, Zhang M and Jiang TM: Trimetazidine hydrochloride as a new treatment for patients with peripheral vascular disease - an exploratory trial. Eur Rev Med Pharmacol Sci 20: 188-193, 2016.

10. Lawall H, Pokrovsky A, Checinski P, Ratushnyuk A, Hamm G, Randerath O, Grieger F and Bentz JWG: Efficacy and safety of alprostadil in patients with peripheral arterial occlusive disease Fontaine Stage IV: Results of a placebo controlled randomised multicentre trial (ESPECIAL). Eur J Vasc Endovasc Surg 53: 559-566, 2017.

11. Huang PP, Li SZ, Han MZ, Xiao ZJ, Yang RC, Qiu LG and Han ZC: Autologous transplantation of peripheral blood stem cells as an effective therapeutic approach for severe arteriosclerosis obliterans of lower extremities. Thromb Haemost 91: 606-609, 2004.

12. Zheng GY, Zhan JH, Luo JH and Cheng X: Effect of alprostadil on wound healing of scalded rats and the mechanism. Zhonghua Shao Shang Za Zhi 34: 380-385, 2018 (In Chinese).

13. Stary CM, Kohin S, Samaja M, Howlett RA and Hogan MC: Trimetazidine reduces basal cytosolic $\mathrm{Ca}^{2+}$ concentration during hypoxia in single Xenopus skeletal myocytes. Exp Physiol 88: 415-421, 2003.

14. Sun MZ, Liu S and Greenaway FT: Characterization of a fibrinolytic enzyme (ussurenase) from Agkistrodon blomhoffii ussurensis snake venom: Insights into the effects of $\mathrm{Ca}^{2+}$ on function and structure. Biochim Biophys Acta 1764: 1340-1348, 2006.

15. Stoner MC, Calligaro KD, Chaer RA, Dietzek AM, Farber A, Guzman RJ, Hamdan AD, Landry GJ and Yamaguchi DJ; Society for Vascular Surgery: Reporting standards of the Society for Vascular Surgery for endovascular treatment of chronic lower extremity peripheral artery disease. J Vasc Surg 64: e1-e21, 2016.

16. Reinecke H, Unrath M, Freisinger E, Bunzemeier H, Meyborg M, Lüders F, Gebauer K, Roeder N, Berger K and Malyar NM: Peripheral arterial disease and critical limb ischaemia: Still poor outcomes and lack of guideline adherence. Eur Heart J 36: 932-938, 2015.

17. Horie T, Kimura T and Ono K: Emerging novel biomarkers for arteriosclerosis obliterans. J Atheroscler Thromb 23: 171-172, 2016.

18. Hoshino J, Ubara Y, Hara S, Sogawa Y, Suwabe T, Higa Y, Nakanishi S, Sawa N, Katori H, Takemoto F, et al: Quality of life improvement and long-term effects of peripheral blood mononuclear cell transplantation for severe arteriosclerosis obliterans in diabetic patients on dialysis. Circ J 71: 1193-1198, 2007. 
19. Bandinelli F,BartoliF,Perfetto E,Del Rosso A,Moggi-Pignone A, Guiducci S, Cinelli M, Fatini C, Generini S, Gabrielli A, et al: The fibrinolytic system components are increased in systemic sclerosis and modulated by alprostadil (alpha1 ciclodestryn). Clin Exp Rheumatol 23: 671-677, 2005.

20. Saigawa T, Kato K, Ozawa T, Toba K, Makiyama Y, Minagawa S Hashimoto S, Furukawa T, Nakamura Y, Hanawa H, et al: Clinical application of bone marrow implantation in patients with arteriosclerosis obliterans, and the association between efficacy and the number of implanted bone marrow cells. Circ J 68: 1189-1193, 2004.

21. Liu Z, Chen JM, Huang H, Kuznicki M, Zheng S, Sun W, Quan N, Wang L, Yang H, Guo HM, et al: The protective effect of trimetazidine on myocardial ischemia/reperfusion injury through activating AMPK and ERK signaling pathway. Metabolism 65: 122-130, 2016
22. Rehberger-Likozar A and Šbeštjen M: Influence of trimetazidine and ranolazine on endothelial function in patients with ischemic heart disease. Coron Artery Dis 26: 651-656, 2015.

23. Lacroix R, Sabatier F, Mialhe A, Basire A, Pannell R, Borghi H, Robert S, Lamy E, Plawinski L, Camoin-Jau L, et al: Activation of plasminogen into plasmin at the surface of endothelial microparticles: A mechanism that modulates angiogenic properties of endothelial progenitor cells in vitro. Blood 110: 2432-2439, 2007.

(i) (8) This work is licensed under a Creative Commons Attribution-NonCommercial-NoDerivatives 4.0 International (CC BY-NC-ND 4.0) License. 